\title{
Review Article \\ Past, Present, and Future of Nerve Conduits in the Treatment of Peripheral Nerve Injury
}

\author{
Aikeremujiang Muheremu ${ }^{1,2,3}$ and Qiang $\mathrm{Ao}^{3}$ \\ ${ }^{1}$ Medical Center, Tsinghua University, Beijing 8610084, China \\ ${ }^{2}$ Department of Orthopedics, Fifth Affiliated Hospital of Xinjiang Medical University, Urumqi, Xinjiang 86838010, China \\ ${ }^{3}$ Institute of Tissue Engineering, China Medical University, No. 77 Puhe Road, Shenyang North New Area, Shenyang, \\ Liaoning 86110122, China
}

Correspondence should be addressed to Qiang Ao; aoqiang@tsinghua.edu.cn

Received 12 February 2015; Revised 12 May 2015; Accepted 19 May 2015

Academic Editor: Aijun Wang

Copyright (C) 2015 A. Muheremu and Q. Ao. This is an open access article distributed under the Creative Commons Attribution License, which permits unrestricted use, distribution, and reproduction in any medium, provided the original work is properly cited.

With significant advances in the research and application of nerve conduits, they have been used to repair peripheral nerve injury for several decades. Nerve conduits range from biological tubes to synthetic tubes, and from nondegradable tubes to biodegradable tubes. Researchers have explored hollow tubes, tubes filled with scaffolds containing neurotrophic factors, and those seeded with Schwann cells or stem cells. The therapeutic effect of nerve conduits is improving with increasing choice of conduit material, new construction of conduits, and the inclusion of neurotrophic factors and support cells in the conduits. Improvements in functional outcomes are expected when these are optimized for use in clinical practice.

\section{Introduction}

Peripheral nerve injuries, which affect 13 to 23 per 100000 persons each year, are one of the main problems in level one trauma centers $[1,2]$. Since most of the patients with peripheral nerve injury are at the peak of their employment productivity, any loss or decrease in function can be particularly devastating [3]. Treatment of injuries to peripheral nerves is one of the most challenging surgical problems. Despite advancements in microsurgical techniques, complete recovery of nerve function after repair has never been achieved [4]. The results of peripheral nerve repair have reached a plateau, with functional recovery still being unsatisfactory, and surgical techniques can hardly be further refined.

Despite early diagnosis and accurate nerve repair with modern surgical techniques, functional recovery never reached the preinjury level. Poor outcomes result from factors both intrinsic and extrinsic to the nervous system, such as the type and level of injury, integrity of the surrounding tissues, the timing of the surgery, and changes in spinal cord neurons and end organs [5-7]. Misdirection of regenerating axons at the injury site is still a major problem. Therefore, interest is increasing in the role of microenvironmental factors in regulating accurate axonal regeneration.

Different from the central nervous system, the peripheral nervous system has strong potential for regeneration. Within an appropriate microenvironment, the regenerating axons extend their processes into the distal bands of Bunger to restore the function of end organs. Traditional epineurium neurorrhaphy for peripheral nerve injury induces regeneration by direct contact, which leads to enforced inosculation and inappropriate coaptation of nerve fascicles, which may result in neuroma. Nerve grafting remains the gold standard of care in addressing peripheral nerve injuries that cannot be bridged by direct epineural suturing [8]. However, the autologous nerve graft is very limited and not readily available; the process of harvesting autologous nerve graft results in morbidity, scarring, sensory loss, and neuroma formation at the site of harvest [9-11]. Thus, it is necessary to take a different approach than direct neurorrhaphy and nerve grafting to achieve satisfactory functional recovery with little complications, particularly in patients with extensive peripheral nerve injury and insufficient amount of donor nerve for harvest. 


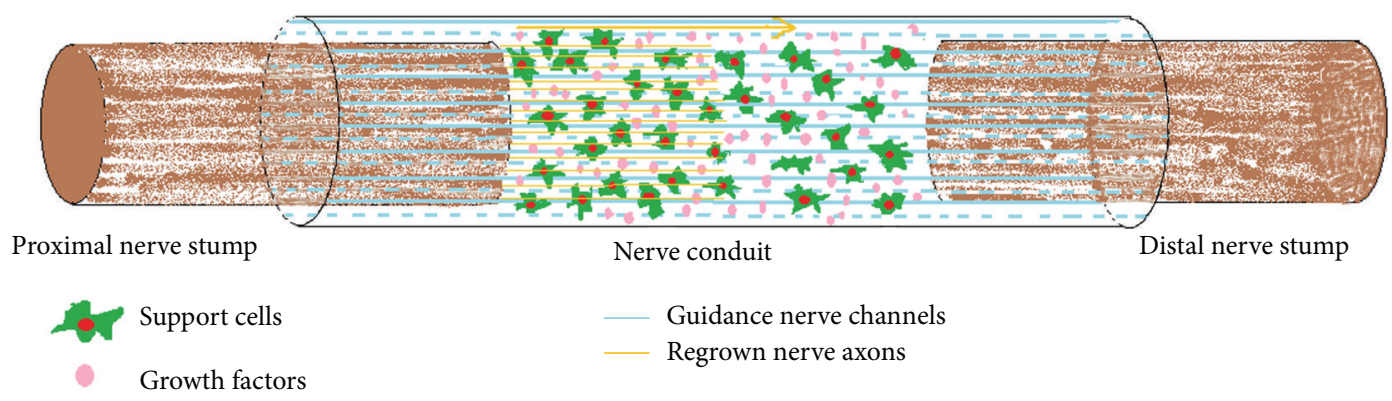

FIGURE 1: The preferable microenvironment created by the nerve conduit that promotes selective nerve regeneration.

\section{An Alternative to Nerve Autograft}

Application of nerve conduits can effectively solve the problems of direct nerve suturing and nerve grafting. In nerve conduit bridging technique, proximal and distal nerve stumps would be inserted into the two ends of a nerve conduit, and axons regenerating from the proximal stump grow through the conduit and selectively grew into their original pathways in the distal stump. The conduit provides trophic support for both stumps and prevents the invasion of the surrounding tissues into the gap between two stumps. Moreover, nerve conduits enrich the neurotrophic factors within the chamber and build a microenvironment, which enhances axonal regeneration after injury (Figure 1).

Since Cajal [12] proposed the hypothesis of nerve chemotaxis, nerve conduit bridging has been developed and gradually used in the clinic. Brushart et al. [13], in their study grafting rat sciatic nerves with nerve conduits, found that the microenvironment produced by nerve conduit is beneficial for robust and accurate nerve regeneration and functional recovery. In other series of studies, Koerber et al. [14] reported better recovery using nerve conduits than direct nerve suturing in animal subjects. Meek and Coert [15] persuaded the EU and US Food and Drug Administration to test the effectiveness of various absorbable nerve conduits. Weber et al. [16] performed a randomized controlled study of 136 patients with peripheral nerve injury in 5 US medical centers. Patients were randomly distributed to polyglycolic acid (PGA) bridging or direct suturing groups: $91 \%$ of the PGA group reported satisfactory healing results as compared with $49 \%$ of the direct suturing group. Taras et al. [17] performed peripheral nerve conduit repair in 73 patients with peripheral nerve injuries, and, except for 2 patients with allergy, all the other patients reported satisfactory recovery. Ashley et al. [18] used a NeuraGen conduit to treat 7 infants with obstetric brachial plexus palsy. All infants gained satisfactory nerve functions and did not suffer from any complications.

Summarizing from the current animal studies and clinical trials, artificial nerve conduit grafting method is superior to direct suturing and autologous nerve grafting in that conduits can be easily prepared, can be shaped into any size, can be readily available in the surgery, can prevent the functional loss at the donor site, and can promote the axonal regeneration accuracy after nerve injury.

\section{Desirable Properties of Nerve Guidance Conduits}

In order to provide ideal scaffold and channel for axonal regeneration, the materials of the nerve guidance conduits should have the following physical properties [19-21].

3.1. Permeability. Nutrients and oxygen need to diffuse into the site of regeneration before the tube becomes vascularized. In addition, permeability might be needed to ensure viability of supportive cells if added.

3.2. Flexibility. Nerve conduits should be flexible to avoid causing mechanical injury to the surrounding tissues and regenerating axons. It is especially important when the nerve conduit is sutured over a joint.

3.3. Swelling. Inappropriate swelling could block the tunnel and prevent nerve regeneration through the conduit or directly injure the regenerated nerve in the conduit.

3.4. Rate of Degradation. The ideal nerve conduit should remain intact before the axons grow from the proximal stump through the gap to reinnervate the distal nerve pathways and then degrade gradually with minimal swelling or the surrounding tissues $[22,23]$. If the degradation process is too fast, it may lead to swelling and focal inflammation. On the other hand, if it is too slow, the conduit could compress the nerve and cause chronic immune rejection.

\section{Materials for the Making of Nerve Guidance Conduits}

Depending on the original conduit material and manufacturing process, nerve conduits can be divided into biological and synthetic nerve conduits.

4.1. Biological Conduits. Biological conduits such as autologous arteries, veins, muscle, and isotype-variant or heterogeneous collagen tubes denatured skeletal muscle or muscle basal lamina [24, 25], human amniotic membrane [26], veins [27], and polyglycolic acid-collagen tubes [28]. Biomaterials such as vein, artery, muscle [29], and umbilical cord vessels 
have been widely used to repair relatively short nerve defects. These materials can provide support for the nerve in the short term and degrade to innocuous products after complete nerve regeneration. Some authors have used autogenetic epineurium [30, 31], normal nerve trunks [32], autogenic veins and autogenic small arteries, and even muscle fibers [33-37] to repair peripheral nerve injury and reported satisfying results.

\subsection{Synthetic Nerve Conduits. They include nondegradable} and degradable nerve conduits.

4.2.1. Nondegradable Nerve Conduits: Silicone, Plastic, and Polytetrafluoroethylene Tubes. The silica gel canal was the earliest artificial conduit [38, 39]. Lundborg et al. [40, 41] used silicon tubes to repair nerve defects. Hollow silicon tubes have been used to repair less than $1 \mathrm{~cm}$ long nerve defects in rat sciatic nerve [42], and silicone tubes filled with SCs have been used to repair a $1.5 \mathrm{~cm}$ defect in rat sciatic nerve [43]. Although nondegradable nerve conduits eliminated the need to harvest autologous nerves, they always cause inflammation of the surrounding tissues and compression of nerve that could affect the regeneration of nerve axons [44]. Another disadvantage of those conduits is that they require a second surgery for removal, which could cause pain and more injury to the patient.

4.2.2. Degradable Nerve Conduits. The commonly used degradable materials include collagen $[45,46]$, chitin [4749], polyglycolic acid conduit, polylactic acid conduit, glycolide trimethylene carbonate conduit, polylactic acid conduit [50], polycarbolacton conduit, poly(lactide-co-glycolide)conduit, natural collagen, and hydrogel conduit.

Rosen et al. [51] compared autologous nerve graft alone and PGA plus type I collagen (extracellular matrix) grafting to bridge $5 \mathrm{~mm}$ defects in rat femoral nerve. After 11 months, autologous nerve graft was found superior to PGA grafting only by means of axonal diameter, but having no difference by means of axonal count or electrophysiologic or functional characteristics between the techniques. den Dunnen et al. [52] used poly (DL-lactide-epsilon-caprolactone) nerve guides and autologous nerve grafts to repair rat sciatic nerve defects. Application of biodegradable nerve conduits resulted in faster and qualitatively better nerve regeneration across a short nerve gap $(1 \mathrm{~cm})$ than with autologous nerve grafting method. Poly-3-hydroxybutyrate (PHB) nerve conduits were used to bridge long nerve defect (up to $4 \mathrm{~cm}$ ) of rabbit common peroneal nerve and supported peripheral nerve regeneration up to 63 days and were proved to be suitable for bridging long nerve defects [53].

Researchers are enthusiastically investigating new biodegradable materials with excellent physical and chemical properties. Biodegradable chitosan-collagen and collagen tubes were proved to promote the growth of axons [54]. However, hollow biodegradable materials can be used to repair only relatively short nerve defects, and the functional recovery is still not satisfying. The combined use of fibronectin mats [55], allogeneic SCs $[56,57]$, ectogenous neurotrophic factors, and bridging tubes was proved to enhance neural regeneration after the injury [58]. PGA collagen tubes filled with collagen sponge and fibers infiltrated with laminae have repaired nerve defect of up to $8 \mathrm{~cm}$ in common peroneal nerves in dog [59]. This is the longest distance repaired by artificial nerve bridging so far.

\section{Bioengineering of Conduits and Seeding with Support Cells}

Tissue engineering techniques can be powerful modalities to improve the effectiveness of nerve conduit bridging. SCs have bioactivity and can produce nerve growth factors. Adherent molecules on the surface of SCs can secrete extracellular matrix and guide the growth of axons. Neurotrophic factors secreted by SCs may be the most important factors in the microenvironment for regenerating axons [60, 61]. SCs or stem cells with ordered scattering in tubes, similar to the bands of Bunger, may promote the growth of nerve axons. Nerve tubes with special 3D structure can include the regenerating axons and can mechanically guide axons [62]. Bioabsorbable and compound conduits (consisting of neurotrophic factors [63], nerve supporters [64, 65], SCs [66], and neural stem cells [67-69]) have promoted chemotactic regeneration of peripheral nerves and enhanced the effectiveness of nerve repair.

Gulati et al. [61] used cultured SC acellular grafts to repair $2 \mathrm{~cm}$ defects in rat peroneal nerve and found host axonal regeneration earlier and significantly better than hollow acellular grafts. Bunting et al. [70] introduced the use of bioabsorbable glass fibers with potential for the most challenging clinical cases that require bridging long interstump gaps. Sundback et al. [71] compared the use of poly(glycerol sebacate) (PGS) and poly(lactide-co-glycolide) PLGA by means of SC metabolic activity, attachment, proliferation, and apoptosis in vitro and found that PGS is an excellent candidate for neural reconstruction. Hadlock et al. [72] created polymer foam conduits with longitudinally aligned channels to implant SCs to provide a suitable environment for axonal regeneration. The polymer foam-processing method and unique channeled architecture allowed for controlled introduction of neurotrophic factors into the conduit. Fansa and Keilhoff [73] cultured isogenic SCs and implanted them into acellular autologous matrix: veins, muscles, nerves, and epineurium tubes. Good regeneration was noted in the muscle-SC group and impaired regeneration quality in the other groups (with or without SCs). The muscle-SC graft showed a systematic and organized regeneration, including a proper orientation of regenerating fibers. All venous and epineurium grafts showed more disorganized regeneration. Varejão et al. [74] compared functional peripheral nerve recovery in the rat sciatic nerve model after reconstruction of a $10 \mathrm{~mm}$ gap with a biodegradable poly(DLLA-epsilon-CL) nerve guide filled with fresh skeletal muscle or phosphatebuffered saline. Motor functional recovery was greater in the muscle-grafting group, with significant difference between 8 and 12 weeks. Axon regeneration progression was better with muscle-enriched tubes, especially from the distal nerve stump, than with hollow conduits. 


\section{Towards Use in Clinical Practice}

In the last several decades, nerve conduits have been used in clinical practice and have significantly improved the functional recovery after peripheral nerve injury [75-78]. In the clinical trial of Chiu et al. [30], 22 patients with 34 nerve injuries were effectively repaired with autologous vein grafts as nerve conduits when selectively applied to bridge a small nerve gap $(\leq 3 \mathrm{~cm})$. Gu et al. [76] used chitosan/PGA nerve guidance channels to repair a $30 \mathrm{~mm}$ long median nerve defect in the right distal forearm of a 55-year-old male. Three years after the surgery, the patient showed satisfactory sensorial as well as functional recovery.

\section{Future Prospects}

Biodegradable nanomaterials are promising for manufacturing novel nerve conduits $[79,80]$. Adequate density and 3D structure of scaffolds imbedded with SCs can lead to forming structures similar to bands of Bunger to enhance the regrowth of axons in peripheral nerve injury. To avoid immune rejection, SCs can be taken from umbilical stem cells or other tissues such as autologous adipose tissues. With the combined application of tissue, cell, and genetic engineering techniques, better functional recovery can be achieved after the peripheral nerve injury in the future.

\section{Conflict of Interests}

The authors declare that there is no conflict of interests regarding the publication of this paper.

\section{Acknowledgments}

This work was supported by the National High Technology Research and Development Program of China ("863" Program, no. 2012AA020905), the National Natural Science Foundation of China (81360194), and the Chow Tai Fook Medical Research Special Fund (202836019-03).

\section{References}

[1] J. D. Amparo Gutierrez, "Peripheral nerve injury," in Neuromuscular Disorders in Clinical Practice, pp. 863-869, 2014.

[2] M. C. O. Rodrigues, A. A. Rodrigues Jr., L. E. Glover, J. Voltarelli, and C. V. Borlongan, "Peripheral nerve repair with cultured schwann cells: getting closer to the clinics," The Scientific World Journal, vol. 2012, Article ID 413091, 10 pages, 2012.

[3] D. Grinsell and C. P. Keating, "Peripheral nerve reconstruction after injury: a review of clinical and experimental therapies," BioMed Research International, vol. 2014, Article ID 698256, 13 pages, 2014.

[4] S. Rochkind and Z. Nevo, "Recovery of peripheral nerve with massive loss defect by tissue engineered guiding regenerative gel," BioMed Research International, vol. 2014, Article ID 327578, 7 pages, 2014.

[5] P. Tang, C. He, L. Zhang, and X. Liu, "A 2-year follow-up survey of 523 cases with peripheral nerve injuries caused by the earthquake in Wenchuan, China," Neural Regeneration Research, vol. 10, no. 2, pp. 252-259, 2015.
[6] C. H. E. Ma, T. Omura, E. J. Cobos et al., "Accelerating axonal growth promotes motor recovery after peripheral nerve injury in mice," The Journal of Clinical Investigation, vol. 121, no. 11, pp. 4332-4347, 2011.

[7] B. He, Z. W. Zhu, Q. T. Zhu et al., "Factors predicting sensory and motor recovery after the repair of upper limb peripheral nerve injuries," Neural Regeneration Research, vol. 9, no. 6, pp. 661-672, 2014.

[8] F. J. Paprottka, P. Wolf, Y. Harder et al., "Sensory recovery outcome after digital nerve repair in relation to different reconstructive techniques: meta-analysis and systematic review," Plastic Surgery International, vol. 2013, Article ID 704589, 17 pages, 2013.

[9] J. S. Belkas, M. S. Shoichet, and R. Midha, "Peripheral nerve regeneration through guidance tubes," Neurological Research, vol. 26, no. 2, pp. 151-160, 2004.

[10] P. Staniforth and T. R. Fisher, "The effects of sural nerve excision in autogenous nerve grafting," Hand, vol. 10, no. 2, pp. 187-190, 1978.

[11] G. R. D. Evans, "Peripheral nerve injury: a review and approach to tissue engineered constructs," Anatomical Record, vol. 263, no. 4, pp. 396-404, 2001.

[12] R. S. Cajal, Degeneration and Regeneration of the Nervous System, Oxford University Press, 1928.

[13] T. M. Brushart, J. Gerber, P. Kessens, Y.-G. Chen, and R. M. Royall, "Contributions of pathway and neuron to preferential motor reinnervation," Journal of Neuroscience, vol. 18, no. 21, pp. 8674-8681, 1998.

[14] H. R. Koerber, A. W. Seymour, and L. M. Mendell, "Mismatches between peripheral receptor type and central projections after peripheral nerve regeneration," Neuroscience Letters, vol. 99, no. 1-2, pp. 67-72, 1989.

[15] M. F. Meek and J. H. Coert, "US Food and Drug Administration/Conformit Europe-approved absorbable nerve conduits for clinical repair of peripheral and cranial nerves," Annals of Plastic Surgery, vol. 60, no. 1, pp. 110-116, 2008.

[16] R. A. Weber, W. C. Breidenbach, R. E. Brown, M. E. Jabaley, and D. P. Mass, "A randomized prospective study of polyglycolic acid conduits for digital nerve reconstruction in humans," Plastic and Reconstructive Surgery, vol. 106, no. 5, pp. 1036-1045, 2000.

[17] J. S. Taras, V. Nanavati, and P. Steelman, "Nerve conduits," Journal of Hand Therapy, vol. 18, no. 2, pp. 191-197, 2005.

[18] W. W. Ashley Jr., T. Weatherly, and S. P. Tae, "Collagen nerve guides for surgical repair of brachial plexus birth injury," Journal of Neurosurgery, vol. 105, no. 6, pp. 452-456, 2006.

[19] D. Arslantunali, T. Dursun, D. Yucel, N. Hasirci, and V. Hasirci, "Peripheral nerve conduits: technology update," Medical Devices, vol. 7, pp. 405-424, 2014.

[20] G. C. W. de Ruiter, M. J. A. Malessy, M. J. Yaszemski, A. J. Windebank, and R. J. Spinner, "Designing ideal conduits for peripheral nerve repair," Neurosurgical Focus, vol. 26, no. 2, article E5, 2009.

[21] R. Ikeguchi, R. Kakinoki, H. Tsuji, T. Yasuda, and S. Matsuda, "Peripheral nerve regeneration through a silicone chamber implanted with negative carbon ions: possibility to clinical application," Applied Surface Science, vol. 310, pp. 19-23, 2014.

[22] B. A. Harley, M. H. Spilker, J. W. Wu et al., "Optimal degradation rate for collagen chambers used for regeneration of peripheral nerves over long gaps," Cells Tissues Organs, vol. 176, no. 1-3, pp. 153-165, 2004. 
[23] S. Inkinen, M. Hakkarainen, A.-C. Albertsson, and A. Södergård, "From lactic acid to poly(lactic acid) (PLA): characterization and analysis of PLA and its precursors," Biomacromolecules, vol. 12, no. 3, pp. 523-532, 2011.

[24] S. Geuna, P. Tos, P. Titolo, D. Ciclamini, T. Beningo, and B. Battiston, "Update on nerve repair by biological tubulization," Journal of Brachial Plexus and Peripheral Nerve Injury, vol. 9, no. 1, article 3, 2014.

[25] A. R. Nectow, K. G. Marra, and D. L. Kaplan, "Biomaterials for the development of peripheral nerve guidance conduits," Tissue Engineering. Part B: Reviews, vol. 18, no. 1, pp. 40-50, 2012.

[26] G. E. Davis, E. Engvall, S. Varon, and M. Manthorpe, "Human amnion membrane as a substratum for cultured peripheral and central nervous system neurons," Brain Research, vol. 430, no. 1, pp. 1-10, 1987.

[27] B. Rinker and J. Y. Liau, "A prospective randomized study comparing woven polyglycolic acid and autogenous vein conduits for reconstruction of digital nerve gaps," The Journal of Hand Surgery, vol. 36, no. 5, pp. 775-781, 2011.

[28] T. Kiyotani, M. Teramachi, Y. Takimoto, T. Nakamura, Y. Shimizu, and K. Endo, "Nerve regeneration across a 25-mm gap bridged by a polyglycolic acid-collagen tube: a histological and electrophysiological evaluation of regenerated nerves," Brain Research, vol. 740, no. 1-2, pp. 66-74, 1996.

[29] U. Dornseifer, A. M. Fichter, S. Leichtle et al., "Peripheral nerve reconstruction with collagen tubes filled with denatured autologous muscle tissue in the rat model," Microsurgery, vol. 31, no. 8, pp. 632-641, 2011.

[30] D. T. W. Chiu, I. Janecka, T. J. Krizek, M. Wolff, and R. E. Lovelace, "Autogenous vein graft as a conduit for nerve regeneration," Surgery, vol. 91, no. 2, pp. 226-233, 1982.

[31] M. Siemionow, Y. Demir, and A. L. Mukherjee, "Repair of peripheral nerve defects with epineural sheath grafts," Annals of Plastic Surgery, vol. 65, no. 6, pp. 546-554, 2010.

[32] D. Muir, "The potentiation of peripheral nerve sheaths in regeneration and repair," Experimental Neurology, vol. 223, no. 1, pp. 102-111, 2010.

[33] S. Hall, "Axonal regeneration through acellular muscle grafts," Journal of Anatomy, vol. 190, no. 1, pp. 57-71, 1997.

[34] P. Tos, B. Battiston, D. Ciclamini, S. Geuna, and S. Artiaco, "Primary repair of crush nerve injuries by means of biological tubulization with muscle-vein-combined grafts," Microsurgery, vol. 32, no. 5, pp. 358-363, 2012.

[35] M. E. De Stefano, F. Toni, V. D’Orazi et al., "Therapeutic approaches enhancing peripheral nerve regeneration," Advances in Bioscience and Biotechnology, vol. 4, pp. 53-60, 2013.

[36] F. Sun, K. Zhou, W.-J. Mi, and J.-H. Qiu, "Combined use of decellularized allogeneic artery conduits with autologous transdifferentiated adipose-derived stem cells for facial nerve regeneration in rats," Biomaterials, vol. 32, no. 32, pp. 8118-8128, 2011.

[37] X. Wang, E. Luo, Y. Li, and J. Hu, "Schwann-like mesenchymal stem cells within vein graft facilitate facial nerve regeneration and remyelination," Brain Research, vol. 1383, pp. 71-80, 2011.

[38] G. Lundborg, L. B. Dahlin, N. Danielsen et al., "Nerve regeneration in silicone chambers: influence of gap length and of distal stump components," Experimental Neurology, vol. 76, no. 2, pp. 361-375, 1982.

[39] L. R. Williams, H. C. Powell, G. Lundborg, and S. Varon, "Competence of nerve tissue as distal insert promoting nerve regeneration in a silicone chamber," Brain Research, vol. 293, no. 2, pp. 201-211, 1984.
[40] G. Lundborg, L. B. Dahlin, N. P. Danielsen, H. A. Hansson, and K. Larsson, "Reorganisation and orientation of regenerating nerve fibres, perineurium, and epineurium in pre-formed mesothelial tubes - an experimental study on the sciatic nerve of rats," Journal of Neuroscience Research, vol. 6, no. 3, pp. 265281, 1981.

[41] G. Lundborg, L. Dahlin, D. Dohi, M. Kanje, and N. Terada, "A new type of 'bioartificial' nerve graft for bridging extended defects in nerves," Journal of Hand Surgery, vol. 22, no. 3, pp. 299-303, 1997.

[42] G. Lundborg, L. B. Dahlin, N. Danielsen et al., "Nerve regeneration in silicone chambers: Influence of gap length and of distal stump components," Experimental Neurology, vol. 76, no. 2, pp. 361-375, 1982.

[43] M. Timmer, S. Robben, F. Müller-Ostermeyer, G. Nikkhah, and C. Grothe, "Axonal regeneration across long gaps in silicone chambers filled with Schwann cells overexpressing high molecular weight FGF-2," Cell Transplantation, vol. 12, no. 3, pp. 265277, 2003.

[44] B. Battiston, S. Geuna, M. Ferrero, and P. Tos, "Nerve repair by means of tubulization: literature review and personal clinical experience comparing biological and synthetic conduits for sensory nerve repair," Microsurgery, vol. 25, no. 4, pp. 258-267, 2005.

[45] K. J. Wangensteen and L. K. Kalliainen, "Collagen tube conduits in peripheral nerve repair: a retrospective analysis," Hand, vol. 5, no. 3, pp. 273-277, 2010.

[46] W. Daly, L. Yao, D. Zeugolis, A. Windebank, and A. Pandit, "A biomaterials approach to peripheral nerve regeneration: bridging the peripheral nerve gap and enhancing functional recovery," Journal of the Royal Society Interface, vol. 9, no. 67, pp. 202-221, 2012.

[47] P. Ramburrun, P. Kumar, Y. E. Choonara, D. Bijukumar, L. C. $\mathrm{du}$ Toit, and V. Pillay, "A review of bioactive release from nerve conduits as a neurotherapeutic strategy for neuronal growth in peripheral nerve injury," BioMed Research International, vol. 2014, Article ID 132350, 19 pages, 2014.

[48] S. Duda, L. Dreyer, P. Behrens et al., "Outer electrospun polycaprolactone shell induces massive foreign body reaction and impairs axonal regeneration through 3D multichannel chitosan nerve guides," BioMed Research International, vol. 2014, Article ID 835269, 16 pages, 2014.

[49] H. W. Liu, W. S. Wen, M. Hu et al., "Chitosan conduits combined with nerve growth factor microspheres repair facial nerve defects," Neural Regeneration Research, vol. 8, no. 33, pp. 31393147, 2013.

[50] F. Xie, F. L. Qing, B. Gu, K. Liu, and X. S. Guo, "In vitro and in vivo evaluation of a biodegradable chitosan-PLA composite peripheral nerve guide conduit material," Microsurgery, vol. 28, no. 6, pp. 471-479, 2008.

[51] J. M. Rosen, J. A. Padilla, K. D. Nguyen, M. A. Padilla, E. E. Sabelman, and H. N. Pham, "Artificial nerve graft using collagen as an extracellular matrix for nerve repair compared with sutured autograft in a rat model," Annals of Plastic Surgery, vol. 25 , no. 5 , pp. $375-387,1990$.

[52] W. F. A. den Dunnen, B. van der Lei, J. M. Schakenraad et al., "Poly(DL-lactide- $\varepsilon$-caprolactone) nerve guides perform better than autologous nerve grafts," Microsurgery, vol. 17, no. 7, pp. 348-357, 1996.

[53] R. C. Young, G. Terenghi, and M. Wiberg, "Poly-3-hydroxybutyrate (PHB): a resorbable conduit for long-gap repair in 
peripheral nerves," British Journal of Plastic Surgery, vol. 55, no. 3, pp. 235-240, 2002.

[54] B. D. Walters and J. P. Stegemann, "Strategies for directing the structure and function of three-dimensional collagen biomaterials across length scales," Acta Biomaterialia, vol. 10, no. 4, pp. 1488-1501, 2014.

[55] F. Gonzalez-Perez, E. Udina, and X. Navarro, "Extracellular matrix components in peripheral nerve regeneration," International Review of Neurobiology, vol. 108, pp. 257-275, 2013.

[56] L. Zhao, W. Qu, Y. Wu, H. Ma, and H. Jiang, "Dorsal root ganglion-derived Schwann cells combined with poly(lactic-coglycolic acid)/chitosan conduits for the repair of sciatic nerve defects in rats," Neural Regeneration Research, vol. 9, no. 22, pp. 1961-1967, 2014.

[57] C. O. Goulart, S. Jürgensen, A. Souto et al., "A combination of schwann-cell grafts and aerobic exercise enhances sciatic nerve regeneration," PLoS ONE, vol. 9, no. 10, 2014.

[58] T. Gordon, "Neurotrophic factor expression in denervated motor and sensory Schwann cells: relevance to specificity of peripheral nerve regeneration," Experimental Neurology, vol. 254, pp. 99-108, 2014.

[59] T. Toba, T. Nakamura, A. K. Lynn et al., "Evaluation of peripheral nerve regeneration across an 80 -mm gap using a polyglycolic acid (PGA) - collagen nerve conduit filled with lamininsoaked collagen sponge in dogs," The International Journal of Artificial Organs, vol. 25, no. 3, pp. 230-237, 2002.

[60] A. R. Nectow, K. G. Marra, and D. L. Kaplan, "Biomaterials for the development of peripheral nerve guidance conduits," Tissue Engineering Part B: Reviews, vol. 18, no. 1, pp. 40-50, 2012.

[61] A. K. Gulati, D. R. Rai, and A. M. Ali, “The influence of cultured Schwann cells on regeneration through acellular basal lamina grafts," Brain Research, vol. 705, no. 1-2, pp. 118-124, 1995.

[62] M. L. Ceci, C. Mardones-Krsulovic, M. Sánchez, L. E. Valdivia, and M. L. Allende, "Axon-Schwann cell interactions during peripheral nerve regeneration in zebrafish larvae," Neural Development, vol. 9, article 22, 2014.

[63] S. P. Lacour, J. J. Fitzgerald, N. Lago, E. Tarte, S. McMahon, and J. Fawcett, "Long micro-channel electrode arrays: a novel type of regenerative peripheral nerve interface," IEEE Transactions on Neural Systems and Rehabilitation Engineering, vol. 17, no. 5, pp. 454-460, 2009.

[64] C.-J. Chang, "Effects of nerve growth factor from genipincrosslinked gelatin in polycaprolactone conduit on peripheral nerve regeneration - in vitro and in vivo," Journal of Biomedical Materials Research Part A, vol. 91, no. 2, pp. 586-596, 2009.

[65] E. Emel, S. S. Ergün, D. Kotan et al., "Effects of insulin-like growth factor-I and platelet-rich plasma on sciatic nerve crush injury in a rat model: laboratory investigation," Journal of Neurosurgery, vol. 114, no. 2, pp. 522-528, 2011.

[66] A. F. Rosenberg, J. Isaacman-Beck, C. Franzini-Armstrong, and M. Granato, "Schwann cells and deleted in colorectal carcinoma direct regenerating motor axons towards their original path," The Journal of Neuroscience, vol. 34, no. 44, pp. 14668-14681, 2014.

[67] P. G. di Summa, D. F. Kalbermatten, E. Pralong, W. Raffoul, P. J. Kingham, and G. Terenghi, "Long-term in vivo regeneration of peripheral nerves through bioengineered nerve grafts," Neuroscience, vol. 181, pp. 278-291, 2011.

[68] S. Marconi, G. Castiglione, E. Turano et al., "Human adiposederived mesenchymal stem cells systemically injected promote peripheral nerve regeneration in the mouse model of sciatic crush," Tissue Engineering Part A, vol. 18, no. 11-12, pp. 12641272, 2012.

[69] A. Chaudhuri and N. Bhattacharya, "Human neural stem cell transplants in neurological disorders: current trends and future options," in Human Fetal Tissue Transplantation, pp. 265-268, Springer, London, UK, 2013.

[70] S. Bunting, L. Di Silvio, S. Deb, and S. Hall, "Bioresorbable glass fibres facilitate peripheral nerve regeneration," Journal of Hand Surgery, vol. 30, no. 3, pp. 242-247, 2005.

[71] C. A. Sundback, J. Y. Shyu, Y. Wang et al., "Biocompatibility analysis of poly(glycerol sebacate) as a nerve guide material," Biomaterials, vol. 26, no. 27, pp. 5454-5464, 2005.

[72] T. Hadlock, C. Sundback, D. Hunter, M. Cheney, and J. P. Vacanti, "A polymer foam conduit seeded with Schwann cells promotes guided peripheral nerve regeneration," Tissue Engineering, vol. 6, no. 2, pp. 119-127, 2000.

[73] H. Fansa and G. Keilhoff, "Comparison of different biogenic matrices seeded with cultured Schwann cells for bridging peripheral nerve defects," Neurological Research, vol. 26, no. 2, pp. 167-173, 2004.

[74] A. S. P. Varejão, A. M. Cabrita, S. Geuna et al., "Functional assessment of sciatic nerve recovery: biodegradable poly (DLLA- $\varepsilon-C L)$ nerve guide filled with fresh skeletal muscle," Microsurgery, vol. 23, no. 4, pp. 346-353, 2003.

[75] J.-Y. Lee, G. Giusti, P. F. Friedrich et al., "The effect of collagen nerve conduits filled with collagen-glycosaminoglycan matrix on peripheral motor nerve regeneration in a rat model," The Journal of Bone and Joint Surgery-American Volume, vol. 94, no. 22, pp. 2084-2091, 2012.

[76] J. Gu, W. Hu, A. Deng, Q. Zhao, S. Lu, and X. Gu, "Surgical repair of a $30 \mathrm{~mm}$ long human median nerve defect in the distal forearm by implantation of a chitosan-PGA nerve guidance conduit," Journal of Tissue Engineering and Regenerative Medicine, vol. 6, no. 2, pp. 163-168, 2012.

[77] M. Griffin, M. Malahias, S. Hindocha, and W. S. Khan, "Peripheral nerve injury: principles for repair and regeneration," The Open Orthopaedics Journal, vol. 8, no. 1, pp. 199-203, 2014.

[78] C. Y. Tseng, G. Hu, R. T. Ambron, and D. T. W. Chiu, "Histologic analysis of Schwann cell migration and peripheral nerve regeneration in the autogenous venous nerve conduit (AVNC)," Journal of Reconstructive Microsurgery, vol. 19, no. 5, pp. 331340, 2003.

[79] X. Zhan, M. Gao, Y. Jiang et al., "Nanofiber scaffolds facilitate functional regeneration of peripheral nerve injury," Nanomedicine: Nanotechnology, Biology, and Medicine, vol. 9, no. 3, pp. 305-315, 2013.

[80] X. Jiang, R. Mi, A. Hoke, and S. Y. Chew, "Nanofibrous nerve conduit-enhanced peripheral nerve regeneration," Journal of Tissue Engineering and Regenerative Medicine, vol. 8, no. 5, pp. 377-385, 2014. 


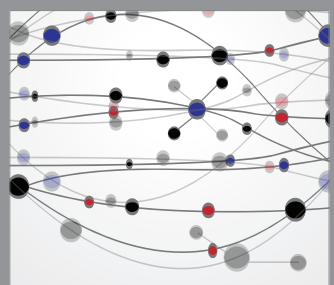

The Scientific World Journal
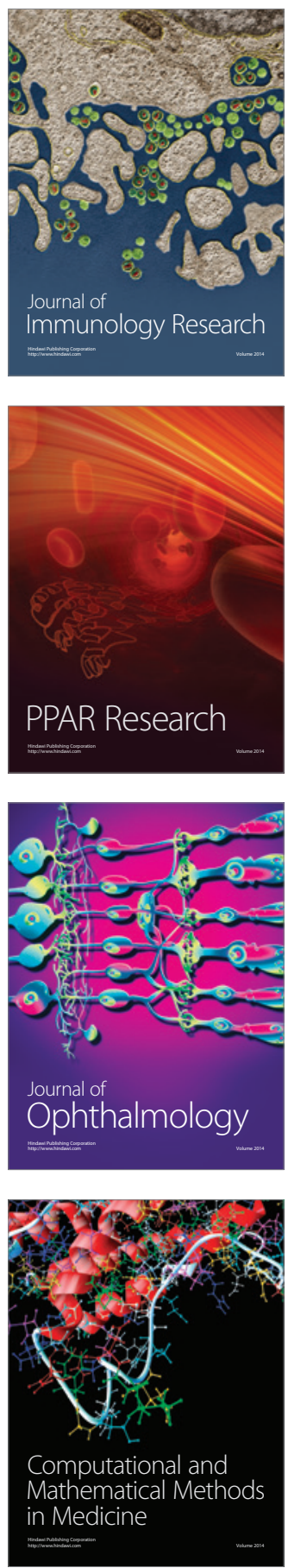

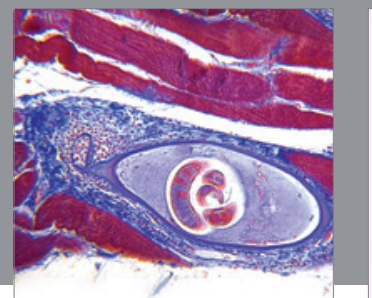

Gastroenterology

Research and Practice
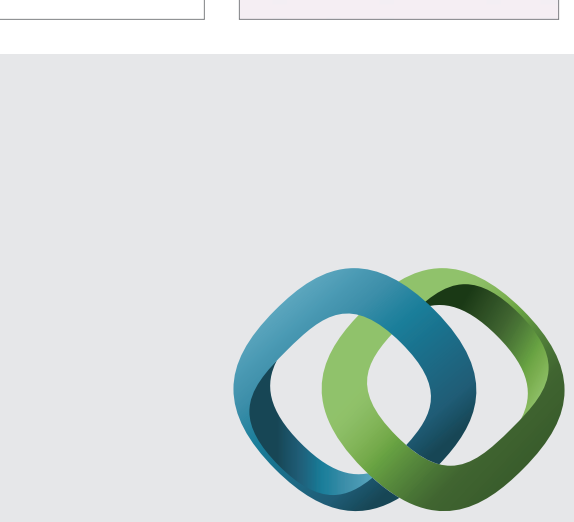

\section{Hindawi}

Submit your manuscripts at

http://www.hindawi.com
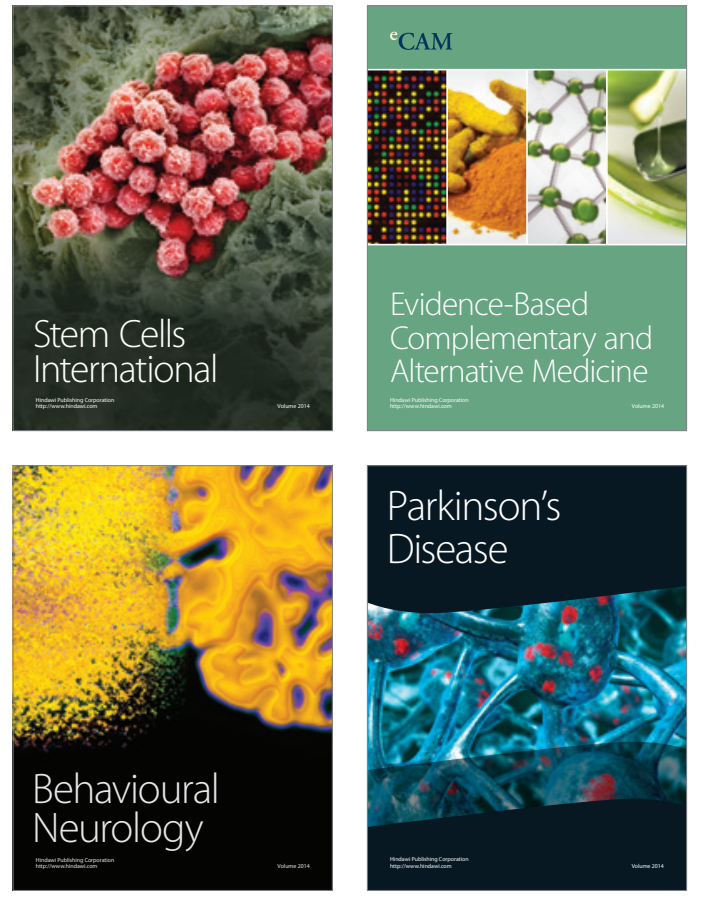
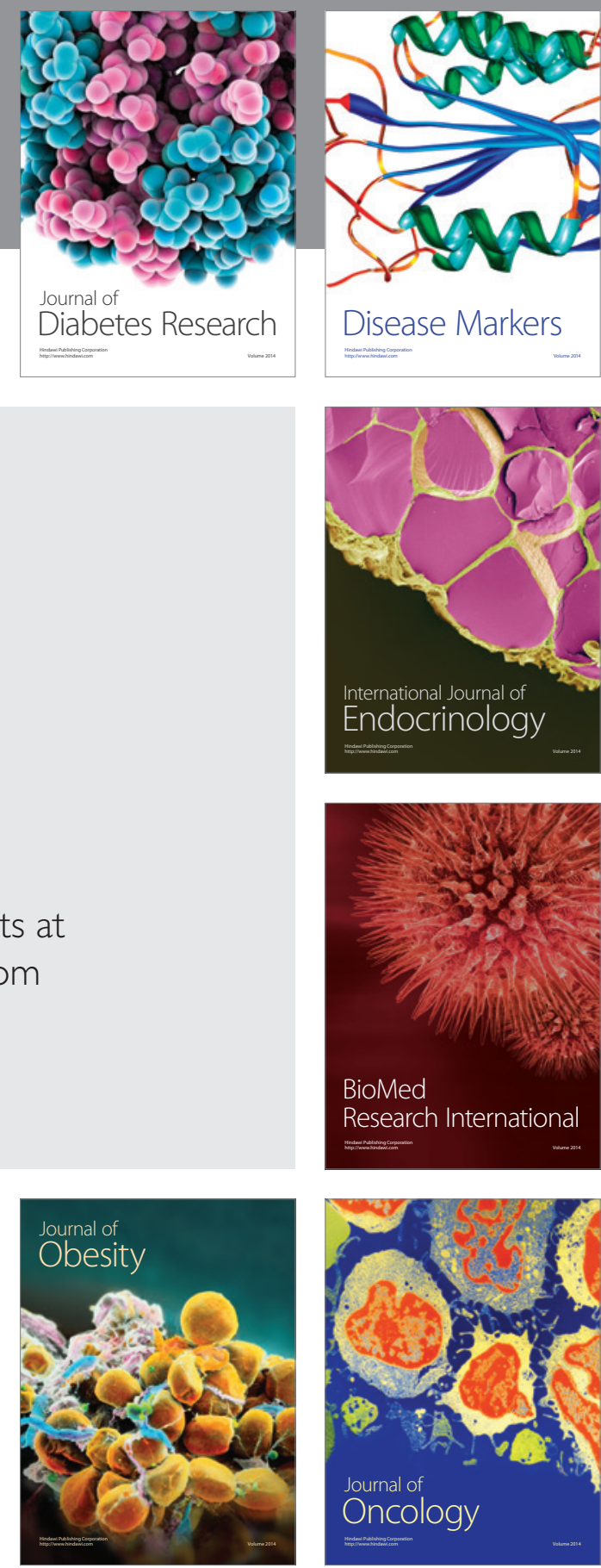

Disease Markers
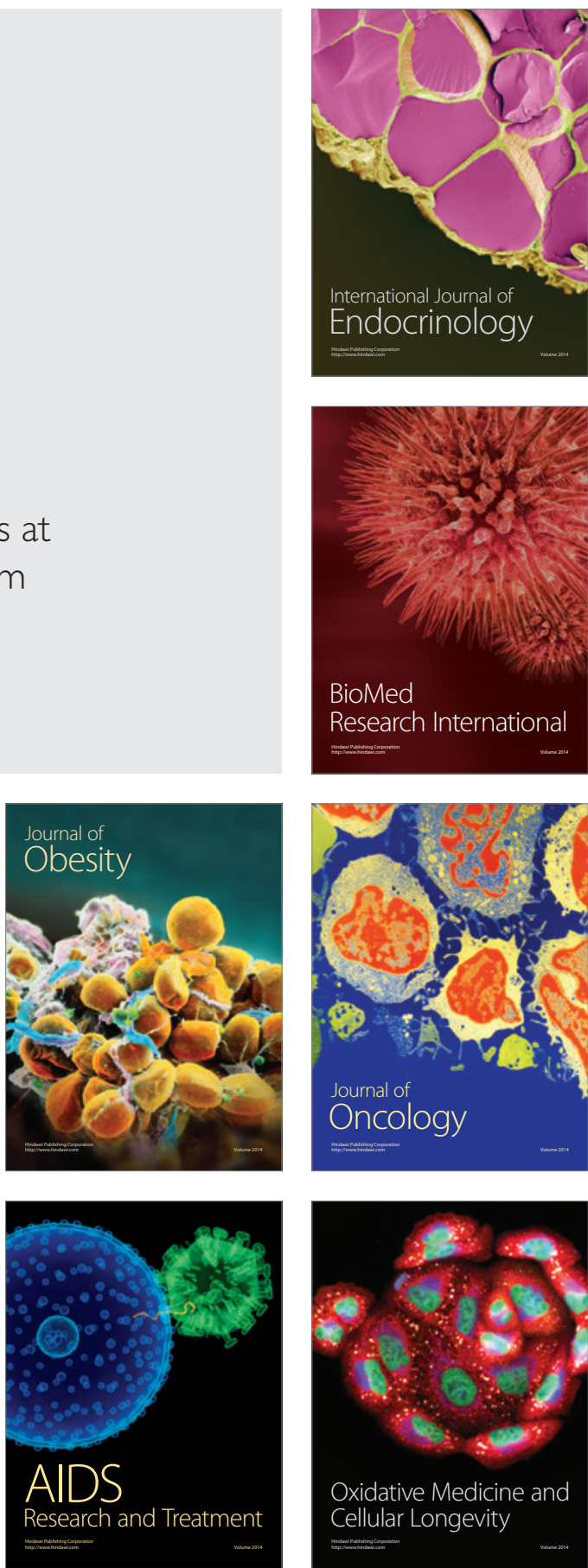